\title{
Anesthesia and analgesia for shoulder surgery
}

\section{Ahmet Eroglu*}

Anesthesiology and Intensive Care Medicine, Karadeniz Technical University, Trabzon, Turkey
Received: 19 August, 2020

Accepted: 01 September, 2020

Published: 02 September, 2020

*Corresponding author: Ahmet Eroglu, Anesthesiology and Intensive Care Medicine, Karadeniz Technical University, Trabzon, Turkey, E-mail: aheroglu@hotmail.com

Keywords: Shoulder surgery; Anesthesia; Analgesia; Interscalene; Nerve block

https://www.peertechz.com

Check for updates

\begin{abstract}
The shoulder is very important for a vertical body position and cosmetic appearance particularly in women. The shoulder joint has the largest motion range of all joints in the human body. All of the shoulder procedures need adequate anesthesia and analgesia for both the comfort of the patients and an early use of rehabilitation exercise. In current clinical practice general anesthesia or nerve blocks like infiltration and interscalene can be used for shoulder surgeries. When compared the anesthesia and analgesia techniques for shoulder surgery we should consider the effectiveness of pain control, incidence of side effects, and patient satisfaction of the techniques.
\end{abstract}

\section{Introduction}

The shoulder and its joint are very important parts of the human body. The shoulder is very important for a vertical body position and cosmetic appearance particularly in women. The shoulder joint has the largest motion range of all joints in the human body [1]. There are some shoulder surgery procedures such as diagnostic arthroscopy, subacromial disorders (impingement syndrome, rotator cuff defects and ruptures, periarthritis humeroscapularis, tendinopathy), arthroscopic subacromial decompression, rotator cuff tears (superficial, articular, full-thickness). All of these shoulder procedures need anesthesia and analgesia. Adequate pain relief after the surgical procedures of shoulder is necessary both for the comfort of the patients and for an early use of rehabilitation exercises [2]. The purpose of this article is to discuss the anesthesia and analgesia methods for the shoulder surgical procedures and highlight some suggestions in this field.

\section{Anesthesia and analgesia techniques for shoulder surgery}

In current clinical practice general anesthesia, regional anesthesia or nerve blocks can be used for shoulder surgeries. The effect of anesthetic technique on perioperative outcomes of shoulder surgery is controversial. Regional anesthesia techniques provide important advantages compared with general anesthesia in some surgical procedures [3-6]. Regional anesthesia is not only performed for adequate anesthesia in the surgical procedures. There are other advantages for the use of regional anesthesia techniques including excellent pain control, reduced side effects, decreased blood loss, improved cardiac and pulmonary function, and shortened stay in the Post-Anesthesia Care Unit (PACU) [3-7]. However regional anesthesia techniques have some complications such Horner's syndrome, hoarseness, systemic local anesthetic toxicity, ipsilateral diaphragmatic paresis, phrenic nerve palsy and other nerve injuries [8-10].

Improvement in ultrasound technology may increase clinical applications for peripheral nerve and truncal blocks. Real time ultrasound using while performing the block may reduce the complications, performance time, and local anesthetic requirements. It also provides reappraising the older techniques with carrying potential complications. The rate of success may increase with clinical experience. Peripheral nerve blocks seem to lack systemic side effect related to sympathetic blockade and lesser incidence of minor complications including urinary retention when compared with central neuraxial blocks or catheter applications. Peripheral nerve blocks seem to be safer than either central neuraxial blocks or general anesthesia, especially in patients with severe coexisting disease [11]. When using a selective ultrasound-guided interscalene blockade of one nerve root tested by thermal quantitative sensory reduced of local anesthetic volume and thereby a decreased incidence of local anesthetic systemic toxicity and a possible decrease in phrenic nerve palsy [12].

The management of acute postoperative pain after shoulder surgery has been performed using local injection of analgesics 
into the subacromial bursa [13,14], i.v. patient-controlled analgesia (PCA) [15], patient controlled interscalene analgesia $[16,17]$, continuous intrabursal infusion of analgesics $[2,18]$ and costoclavicular block, proximal suprascapular nerve block and supraclavicular nerve block [19]. The number of studies investigating the analgesic efficacy of patient controlled subacromial analgesia remains limited. In a prospective randomized study was firstly compared patient-controlled subacromial analgesia with ropivacaine or fentanyl and patientcontrolled i.v. analgesia with fentanyl after open acromioplasty surgery. In that study, the use of the PCA techniques with subacromial ropivacaine $0.2 \%$ and with i.v. fentanyl $4 \mathrm{mg} / \mathrm{ml}$ at a rate of $5 \mathrm{ml} / \mathrm{h}$ plus a bolus dose of $3 \mathrm{ml}$ with a lockout time of 20 min provided similar and adequate pain relief, minimal sideeffects and high patient satisfaction after open acromioplasty surgery. Whereas the PCA with subacromial fentanyl was not as effective as subacromial ropivacaine or i.v. fentany [2]. Besides, in a retrospective clinical study was reported that patients receiving an interscalene block (ISB) experienced significantly less pain than those receiving a Subacromial Infusion (SAI) and they were discharged home from the PACU in half the time as the patients receiving a SAI. On the basis of the comparative efficacy, the authors concluded that a SAI cannot replace an ISB after outpatient arthroscopic rotator cuff repair [20].

As a nerve block, Interscalene Brachial plexus block (ISB) is used to provide both anesthesia and analgesia for shoulder surgery. In a study the authors showed that the same volume and concentration of bupivacaine and ropivacaine $(30 \mathrm{~mL}$ of $0.5 \%$ ) for interscalene brachial plexus block anesthesia produced similar surgical block. When continuing the block with a patient-controlled interscalene analgesia infusion, $0.15 \%$ bupivacaine and ropivacaine provided adequate pain relief, similar side effects, and high patient satisfaction after shoulder surgery [17]. Comparison of interscalene block, general anesthesia, and intravenous analgesia for outpatient shoulder reduction suggested that clinical outcome was comparable among the three groups, but the shortest overall procedure time and greater patient satisfaction were found in patients with interscalene block [21]. In another retrospective study reported that continuous interscalene brachial plexus blocks yielded continuous pain relief, however, complications such as temporary finger paralysis and drug leakage are concerns [22]. However, ISB raises concerns relating to its high risk of transient and potentially long-term respiratory complications, most notably phrenic nerve paresis and unilateral diaphragmatic paralysis. Persistent phrenic nerve palsy after interscalene block is a complication that has recently gained wider recognition. There are several potential causes of persistent phrenic nerve palsy such nerve damage due to direct needle trauma or intraneural injection has been implicated in case reports of persistent phrenic nerve palsy after landmark-guided interscalene block techniques, but not so far with ultrasound-guided interscalene block. Combined suprascapular and axillary nerve blocks are another alternative to consider in scenarios in which avoiding phrenic nerve palsy is critical, particularly in arthroscopic shoulder surgery [23]. In a review article suggested that there are no clinically meaningful analgesic differences between suprascapular block and interscalene block except for interscalene block providing better pain control during recovery room stay; however, suprascapular block has fewer side effects, in particular those that may limit the use of interscalene blocks in patients with obesity, sleep apnea, or pulmonary disease These findings suggest that suprascapular block may be considered an effective and safe interscalene block alternative for shoulder surgery [8]. To minimize the occurrence of pulmonary complications, some authors conducted regional anesthesia with diaphragmsparing nerve blocks such as costoclavicular block, proximal Suprascapular Nerve Block (SSNB), and supraclavicular nerve block (SCNB). They suggested that costoclavicular block combined with proximal SSNB with SCNB may be a pertinent option for shoulder surgery anesthesia in a patient with reduced pulmonary function [19]. Nevertheless, in a systematic review and meta-analysis suggested that interscalene block with liposomal bupivacaine is comparable with respect to pain relief, the opioid-sparing effect, and adverse effects in the first 48 hours after arthroscopic rotator cuff repair and total shoulder arthroplasty [24].

Single-Shot Interscalene Block (SSISB) of the brachial plexus can provide postoperative analgesia up to eight hours [25] and some beneficial effects like decreasing opioid consumption, and postoperative nausea and vomiting for the patients of shoulder surgery. Bojaxhi, et al. [26] present a new study related to SSISB with periarticular local infiltration analgesia (LIA) for shoulder arthroplasty. In this study, they aimed to evaluate the effect of postoperative pain control, morphine consumption, some side effects like nausea and vomiting and duration of hospital stay for Continue Interscalen Block (CISB) and SSISB in shoulder arthroplasty. They assumed that CISBs have some disadvantages for example cost and waste of time when compared SSISB. And, SSISB with an analgesic cocktail including ropivacaine, morphine, ketorolac and epinephrine may be a good alternative to the CISBs' analgesia. The results of this new study [26] showed that SSISB with LIA provided good postoperative pain control as well as CISB for two days, but rescue morphine consumption was a bit more. However, the patients in the SSISB group had no catheter problems such as catheter failures, catheter discomfort or catheter replacement requests. However there are some limitations of this new study such as the study was conducted a retrospective manner, the investigation of plasma levels of local anesthetics should be performed due to the accidental vascular puncture of the vessels of neck and shoulder and the authors could not evaluate pain scores and opioid or analgesic consumption of the patients after hospital discharge. Consequently, further prospective studies should be conducted in larger groups to investigate side effects, duration of hospital stay, readmission, adverse events or residual symptoms and patient satisfaction. In conclusion, it can be expressed that there is an increasing interest to the periarticular injections of multimodal analgesics to control of postoperative pain in clinical practice. It may be an alternative to the selective nerve blocks because of easy to use and management. Single shot ISB when combined periarticular injections of analgesics can provide effective postoperative analgesia as well as continuous ISB for shoulder arthroplasty. However, the duration of effect of it may be terminated before that of the patients who were administered continuous ISB [1]. 
The influence of surgery type on choosing anesthesia and analgesia methods is another important issue to be discussed. Acromioplasty sub-acromial decompression), stabilisation, adhesiolysis (release of frozen shoulder) and rotator cuff repair are the most common procedures undertaken, and these are usually performed arthroscopically. Open procedures include arthroplasty of the glenohumeral joint, which can be performed as a total or partial joint replacement, open stabilisation (e.g. LatarjeteBristow procedures), open rotator cuff repair, and most trauma procedures. Both arthroscopic (particularly rotator cuff repair and stabilisation) and open shoulder surgery are associated with moderate to severe postoperative pain [9]. Postoperative pain relief, patient satisfaction and side effects of the anesthesia and analgesia methods for shoulder surgery were showed in Table 1.

Table 1: Anesthesia and analgesia methods and side effects for shoulder surgery.

\begin{tabular}{|c|c|c|c|c|}
\hline Methods & $\begin{array}{c}\text { Postoperative } \\
\text { Pain relief }\end{array}$ & Side effect & $\begin{array}{c}\text { Patient } \\
\text { satisfaction }\end{array}$ & References \\
\hline $\begin{array}{c}\text { General } \\
\text { anesthesia }\end{array}$ & not comparable & nausea, vomiting & - & 7,21 \\
\hline $\begin{array}{c}\text { Single } \\
\text { Interscalene }\end{array}$ & good & $\begin{array}{c}\text { more rescue } \\
\text { morphine } \\
\text { consumption }\end{array}$ & - & 1,26 \\
\hline $\begin{array}{c}\text { Continue } \\
\text { Interscalene }\end{array}$ & excellent & $\begin{array}{c}\text { hoarseness, phrenic } \\
\text { nerve palsy }\end{array}$ & high & $2,9,10,17,20,23$ \\
\hline $\begin{array}{c}\text { Subacromial } \\
\text { infusion }\end{array}$ & comparable & fewer & medium & $2,13,18,20$ \\
\hline $\begin{array}{c}\text { Suprascapular } \\
\text { costoclavicular }\end{array}$ & comparable & fewer & - & 8,23 \\
\hline Iv PCA & comparable & fewer & - & 19,23 \\
\hline
\end{tabular}

\section{Conclusion}

When compared the anesthesia and analgesia techniques for shoulder surgery we should consider the effectiveness of pain control, the incidence of side effects, and patient satisfaction of the techniques. In addition, we need prospective multicenter clinical studies in large groups in this field.

\section{References}

1. Eroglu A (2019) Single-shot interscalene block with periarticular local infiltration analgesia for shoulder arthroplasty. Minerva Anestesiol 85: 812813. Link: https://bit.ly/2Dg5xjB

2. Eroglu A (2006) A comparison of patient-controlled subacromial and i.v. analgesia after open acromioplasty surgery. Br J Anaesth 96: 497-501. Link: https://bit.ly/2QFf3Qz

3. Mauermann WJ, Shilling AM, Zuo Z (2006) A comparison of neuraxial block versus general anesthesia for elective total hip replacement: a meta-analysis. Anesth Analg 103: 1018-1025. Link: https://bit.ly/3IByvvM

4. Eroglu A, Saracoglu S, Erturk E, Kosucu M, Kerimoglu S (2010) A comparison of intraarticular morphine and bupivacaine for pain control and outpatient status after an arthroscopic knee surgery under a low dose of spinal anaesthesia. Knee Surgery, Sports Traumatology, Arthroscopy 18: 1487-1495. Link: https://bit.ly/2DmMnsA

5. Macfarlane AJR, Prasad GA, Chan VWS, Brull R (2009) Does regional anaesthesia improve outcome after total hip arthroplasty? A systematic review. Br J Anaesth 103: 335-345. Link: https://bit.ly/34XwRPj
6. Casati A, Borghi B, Fanelli G, Montone N, Rotini R, et al. (2003) Interscalene brachial plexus anesthesia and analgesia for open shoulder surgery: a randomized, double-blinded comparison between levobupivacaine and ropivacaine. Anesth Analg 96: 253-259. Link: https://bit.ly/2DhRyK9

7. Memtsoudis SG, Sun X, Chiu YL, Stundner O, Liu SS, et al. (2013) Perioperative comparative effectiveness of anesthetic technique in orthopedic patients. Anesthesiology 118: 1046-1058. Link: https://bit.ly/3jDU50x

8. Hussain N, Goldar G, Ragina N, Banfield L, Laffey JG, et al. (2017) Suprascapular and interscalene nerve block for shoulder urgery: A systematic review and meta-analysis. Anesthesiology 127: 998-1013. Link: https://bit.ly/3jBO70z

9. Hewson DW, Oldman M, Bedforth NM (2019) Regional anaesthesia for shoulder surgery. BJA Education 19: 98e104. Link: https://bit.ly/3hMxfDJ

10. Eroglu A (2011) A case of transient hoarseness caused by interscalene brachial plexus block in shoulder surgery. Out of the blue E-letters.

11. Kettner SC, Willschke $H$, Marhofer $P$ (2011) Does regional anaesthesia really improve outcome? Br J Anaesth 107: i90-i95. Link: https://bit.ly/3IDUxhi

12. Sermeus LA, Schepens T, Hans GY, Morrison SG, Wouters K, et al. (2019) A low dose of three local anesthetic solutions for interscalene blockade tested by thermal quantitative sensory testing:a randomized controlled trial. J Clin Monit Comput 33: 307-316. Link: https://bit.ly/3jw7fwO

13. Muittari P, Kirvela O (1998) The safety and efficacy of intrabursal oxycodone and bupivacaine in analgesia after shoulder surgery. Reg Anesth Pain Med 23 474-478. Link: https://bit.ly/3bcrOvo

14. Muittari PA, Nelimarkka O, Seppala T, Kanto JH, Kirvelä OA (1999) Comparison of the analgesic effects of intrabursal oxycodone and bupivacaine after acromioplasty. J Clin Anesth 11: 11-16. Link: https://bit.ly/3gMB4aH

15. Borgeat A, Schappi B, Biasca N, Gerber C (1997) Patient-controlled analgesia after major shoulder surgery: PCIA versus PCA. Anesthesiology 87: 13431347. Link: https://bit.ly/2QFhcf5

16. Casati A, Borghi B, Fanelli G, Montone N, Rotini R, et al. (2003) Interscalene brachial plexus anesthesia and analgesia for open shoulder surgery: a randomized, double-blinded comparison between levobupivacaine and ropivacaine. Anesth Analg 96: 253-259. Link: https://bit.ly/2YNB04n

17. Eroglu A, Uzunlar H, Sener M, Akinturk Y, Erciyes N (2004) A clinical comparison of equal concentration and volume of ropivacaine and bupivacaine for interscalene brachial plexus anesthesia and analgesia in shoulder surgery. Reg Anesth Pain Med 29: 539-543. Link: https://bit.ly/3bdHWws

18. Jin-Young P, Gwan-Woo L, Yun K, Yoo (2002) The efficacy of continuous intrabursal infusion with morphine and bupivacaine for postoperative analgesia after subacromial arthroscopy. Reg Anesth Pain Med 27: 145-149. Link: https://bit.ly/3lyMPFg

19. Kwon W, Lee SM, Bang S (2019) Costoclavicular block for shoulder surgery in a patient with tracheobronchopathia osteochondroplastica and COPD. J Clin Anesth 55: 13-14. Link: https://bit.ly/31LuuwP

20. Benjamin D, Gross BD, Paganessi SA, Oscar Vazquez O (2020) Comparison of subacromial injection and interscalene block for immediate pain management after arthroscopic rotator cuff repair. Arthroscopy 36: 1243-1250. Link: https://bit.ly/34RzxxO

21. Kreutziger J, Hirschi D, Fischer S (2019) Comparison of interscalene block general anesthesia, and intravenous analgesia for out-patient shoulder reduction. J Anesth 33: 279-286. Link: https://bit.ly/3bgNZkc

22. Iwashita S, Hashiguchi H, Okubo A, Yoneda M, Takai S (2020) Nerve block for pain relief during arthroscopic rotator cuff repair. J Nippon Med Sch 87: 87-91. Link: https://bit.ly/2QIVbfe

23. El-Boghdadly K, Chin KJ, Chan VWS (2017) Phrenic nerve palsy and regional anesthesia for shoulder surgery. Anatomical, physiologic, and clinical considerations. Anesthesiology 127: 173-191. Link: https://bit.ly/3jB4Lx0 
24. Kolade O, Patel K, Ihejirika R, Press D, Friedlander S, et al. (2019) Efficacy of liposomal bupivacaine in shoulder surgery: a systematic review and metaanalysis. J Shoulder Elbow Surg 28: 1824-1834. Link: https://bit.ly/3gM7qm2

25. Abdallah FW, Halpern SH, Aoyama K, Brull R (2015) Will the real benefits of single-shot interscalene block please stand up? A systematic review and meta-analysis. Anesth Analg 120: 1114-1129. Link: https://bit.ly/2Dijo9h
26. Bojaxhi E, Lumermann LA, Mazer LS, Howe BL, Or- tiguera CJ, et al. (2019) Interscalene brachial plexus catheter versus single-shot interscalene block with periarticular local infiltration analgesia for shoulder arthroplasty. Minerva Anestesiol 85: 840-845. Link: https://bit.ly/34QC1MM
Discover a bigger Impact and Visibility of your article publication with

\section{Peertechz Publications}

\section{Highlights}

* Signatory publisher of ORCID

* Signatory Publisher of DORA (San Francisco Declaration on Research Assessment)

* Articles archived in worlds' renowned service providers such as Portico, CNKI, AGRIS, TDNet, Base (Bielefeld University Library), CrossRef, Scilit, J-Gate etc.

* Journals indexed in ICMJE, SHERPA/ROMEO, Google Scholar etc.

- OAI-PMH (Open Archives Initiative Protocol for Metadata Harvesting)

* Dedicated Editorial Board for every journal

* Accurate and rapid peer-review process

* Increased citations of published articles through promotions

* Reduced timeline for article publication

Submit your articles and experience a new surge in publication services (https://www.peertechz.com/submission).

Peertechz journals wishes everlasting success in your every endeavours.

Copyright: () 2020 Eroglu A. This is an open-access article distributed under the terms of the Creative Commons Attribution License, which permits unrestricted use, distribution, and reproduction in any medium, provided the original author and source are credited. 